\title{
Aprendendo sobre Ditadura Civil-Militar de Segurança Nacional e Terrorismo de Estado Argentina através do Jogo de Cartas
}

\author{
Aprendiendo sobre la Dictadura Civil-Militar de Seguridad Nacional y \\ Terrorismo de Estado Argentina a través de un Juego de Cartas \\ Learning about Argentinian Civil-Military National Security and State \\ Terrorism Dictatorship through a Playing Card Game
}

\author{
Rafael Barbosa de Jesus Santana ${ }^{1}$ \\ Raicilaine Barbosa de Jesus Santana ${ }^{2}$
}

\begin{abstract}
Resumo
Na segunda metade do século XX, a América Latina foi assombrada por governos militares autoritários. Para evitar revoluções comunistas, os Estados Unidos apoiaram militares contra a democracia em muitas nações latinas. Mesmo tendo fatores comuns que caracterizam esses governos ditatoriais, não podemos desatentar para as especificidades das ações desses militares em cada país. Tentando abordar a questão específica da ditadura na Argentina (1976 - 1983), buscando oportunizar aos alunos do ensino fundamental, momentos de reflexão sobre a abordagem de temáticas de História da América nas aulas de História, bem como desenvolvendo habilidades para a confecção de materiais pedagógicos pertinentes para o ensino de tais temáticas, propõe-se um jogo de cartas com o assunto "Argentina: ditadura de Segurança Nacional e Terrorismo de Estado". O jogo nesse contexto, é um material didático que serve de apoio para o professor em sua aula. $\mathrm{O}$ grande objetivo desse jogo é construir uma ideia da ditadura argentina como um evento potencialmente traumático, com foco nas políticas de segurança nacional e Terror de Estado, situando os jogadores nessa sensação de vulnerabilidade, na qual os viventes daquele período experienciaram. Cabe reforçar aqui, que, o jogo não se expressa por si, ou seja, ele é um suporte para o professor utilizá-lo após outras aulas sobre as ditaduras na América Latina.
\end{abstract}

Palavras-Chave: Consciência Histórica; Ditadura Argentina; Jogo de Cartas; Terrorismo de Estado; Trauma Histórico.

\section{Resumen}

En la segunda mitad del siglo 20, Latinoamerica fue asombrada por gobiernos militares autoritários. Bajo el pretexto de evitar revoluciones comunistas, los Estados Unidos de América apoyaron militares contra la democracia en muchas naciones latinoamericanas. Aunque estos gobiernos dictatoriales tengan factores en común que les caracterizen, no podemos desatentar a las especificidades de las acciones de estos regímenes en cada país. Abordando la cuestión específica de la dictadura en Argentina (1976-1983), buscando oportunizar a los alumnos del Primario momentos de reflexión sobre el enfoque de temas de História Latinoamericana en clases de História, bien como desarrollando habilidades para la confección de materiales pedagógicos pertinentes a la enseñanza de tales temas, se propone um juego de cartas con el tema: "Argentina: dictadura de Seguridad Nacional y Terrorismo de Estado". El principal objectivo del juego es construir una idea de la dictatura argentina como un evento potencialmente traumático, lo cual fue experienciado por los vivientes de aquel período, sumergiendo a los jugadores en una sensación de vulnerabilidad. El juego, en ese sentido, es um material de apoyo para que el maestro lo utilice despues de otras clases sobre dictaduras de Latinoamerica.

\footnotetext{
${ }^{1}$ Graduando em História, Universidade Federal do Pampa (UNIPAMPA), Jaguarão, Rio Grande do Sul; rafael.santana.001@ hotmail.com.

2 Bacharel em Produção e Política Cultural, Universidade Federal do Pampa (UNIPAMPA), Jaguarão, Rio Grande do Sul; raici.miss@gmail.com.
} 
Palabras clave: Consciencia Histórica; Dictadura Argentina; Juegos de Cartas; Terrorismo de Estado; Trauma Histórico.

\section{Abstract}

On the second half of the 20th century, Latin America was haunted by authoritarian military regimes. Under the pretext of preventing communist revolutions, the United States of America supported military forces against democracy in many Latin American nations. Although these military regimes have factors in common, the specificity of each regime's actions are not to be disregarded. Approaching the specific issue of the Argentinian dictatorship (1976-1983), aiming to facilitate moments of reflexion on the approach of Latin American History themes in class for Elementary School students, as well as developing abilities for the confection of pedagogical material pertinent to the teaching of such themes, a card game is proposed on the subject "Argentina: National Security and State Terrorism Dictatorship". The main objective of this game is to produce an idea of the Argentine dictatorship as a potentially traumatic event for those who lived through the experience, immersing the players in a feeling of vulnerability. The game, in this sense, is a support material for the teacher to utilize after other lessons on Latin American dictatorships.

Keywords: Historical Awareness; Argentine Dictatorship; Playing Card Games; State Terrorism; Historical Trauma.

\section{Entre história, memória e trauma}

História, "a ciência que estuda o homem no tempo e no espaço", esta é a concepção de José D’Assunção Barros (2005), qual compactuo. Mas porque estudar os feitos dos homens (das mulheres e daquelxs não binários) na história? Conforme Todorov (1995), a história é exemplar, ela pode ser encarada como lição para os sobreviventes do passado, que no presente, não repetem os erros pretéritos. Eventos como a $1^{\mathrm{a}}$ e $2^{\mathrm{a}}$ Guerra Mundial, o Holocausto, a Guerra de Biafra e golpes militares autoritários foram eventos potencialmente traumáticos. Existem atualmente, vários relatos sobre estes eventos, de como eles interferiram e interferem negativamente às vidas individuais e coletivas de várias pessoas e grupos sociais.

Segundo Berkowitz (1965, p.43), uma sobrevivente de Auschwitz, "o silêncio é o verdadeiro crime contra a humanidade". Então, falar sobre tais temáticas e escutar os testemunhos sobre elas é de extrema importância para chegar-se às verdades históricas, reparar os erros cometidos no passado e conscientizar historicamente a população. Ao ouvir os relatos dessas experiências traumáticas, não podemos ignorá-las, devendo nos "colocar" no lugar do outro. Para Todorov (1995), a empatia resultaria na transformação do ambiente e do próprio ser humano. Neste sentido, considero o conceito de empatia central neste artigo.

Para fins de inteligibilidade deste trabalho, utilizo o conceito de trauma histórico levantado por Juan Pablo Borda Bohigas (2015). Para o colombiano, o trauma histórico é um trauma coletivo infligido a um grupo de pessoas que compartilham uma identidade (no caso, a identidade argentina) ou afiliação, que se caracteriza pelo legado transgeracional dos eventos traumáticos vivenciados e se expressa por meio de várias respostas psicológicas e sociais. No 
caso da ditadura argentina, podemos perceber o trauma por dois caminhos: pelos relatos de sobreviventes e de pessoas que perderam amigos, conhecidos e familiares (o legado transgeracional) no período ditatorial, pois demonstram limitações para abordar e discutir, a partir dessa categoria diagnóstica, os traumas coletivos em situação de violência política e social; e podemos também compreender o trauma pelo caminho da latência.

Segundo Gumbrecht (2014), em sua obra Depois de 1945: latência como origem do presente, se referindo ao contexto alemão pós Segunda Guerra Mundial, pouco se falava sobre os massacres da Guerra; quanto mais as condições de vida ficavam piores, mais se percebia os resquícios do conflito na sociedade. Os resquícios, a calmaria superficial da sociedade, o silenciamento sobre um determinado assunto, a falta de digestão do evento traumático seria a latência e o trauma. No caso da ditadura argentina, as palavras de Gumbrecht se adequam perfeitamente: "nunca haverá futuro suficiente para provar-lhes o contrário". O contrário neste sentido, seria a esperança nos seres humanos, na justiça. Para várias famílias que tiveram seus amigos e familiares desaparecidos no período da ditadura, essa reparação talvez nunca ocorra.

Ainda seguindo uma perspectiva gumbrechtiana, acredito que o tempo de calmaria e silenciamento de determinado evento histórico pode impedir o progresso, a ação, pois as ações precisam do futuro para ser motivação da realidade presente. Destarte, é preciso colocar pontos finais em eventos como os ditatoriais.

\section{A ditadura de segurança nacional e terrorismo de estado}

Segundo Alves (1989), a ideologia de Segurança Nacional foi uma doutrina antimarxista e de tendências conservadoras, no contexto da Guerra Fria, em um mundo polarizado entre Estados Unidos e União Soviética (capitalismo e comunismo). Para Padrós (2005), a Doutrina de Segurança Nacional e a Política de Terror de Estado procurava defender os interesses das classes dominantes e o capital estrangeiro. Para além disso, tal estilo de ditadura vinha como uma tentativa de destruição da crescente mobilização dos movimentos sociais e da reivindicação de mudanças estruturais. A censura, a intervenção nas redes de ensino e a perseguição marcaram a expansão autoritária na América Latina. Ainda para Padrós, os Estados ditatoriais buscavam se "defender" contra possíveis agressões externas e internas (comunismo), destruir as organizações revolucionárias, despolitizar os setores populares, aprofundar as relações com os Estados Unidos, acabar com o pluralismo político, interromper a dinâmica eleitoral e impor uma ordem de segurança interna. 
Conforme Alves (1989), a segurança interna pode ser interpretada como ações intermediadas pelo Estado no sentido de criar condições para a preservação dos poderes constituídos, das leis e da ordem. Vale lembra que a aplicação da tortura e do sequestro não começaram com a implantação das ditaduras de Segurança Nacional.

Avaliando tal contexto, Padrós afirma que o resultado foi a instalação da cultura do medo e de um Estado de guerra permanente, não-declarada, em que todos os setores da sociedade estavam propícios à repressão. Por ter essa linha tênue de quem poderia ser um "inimigo", o caos psicológico e o medo passaram a fazer parte do cotidiano das pessoas. Para implementar a segurança nacional era necessário o combate contínuo da oposição, através do extermínio e desaparecimento. No entanto, as iniciativas repressivas não eram apenas a violência física, pois a força não é o único elemento de manutenção do sistema autoritário. $\mathrm{Na}$ luta contra os inimigos internos (os subversivos), o sequestro, o interrogatório, a detenção, a censura, a desinformação e a tortura também eram armas de controle e segurança nacional. $\mathrm{O}$ sistema de Terror de Estado era tão perverso, que a indefinição de alvos, a guerra total, resultava em autocensura, pois o medo estava onipresente (fator generalizante do trauma).

Caracterizando o evento traumático da ditadura na Argentina, Bauer (2012) aponta 8 características:

1. O passado de medo tende a perdurar até os dias atuais;

2. As pessoas que vivenciaram o evento têm dificuldades de elaborar, representar e simbolizar o que ocorreu;

3. Os resultados dessa experiência não se extinguiram com a mudança do regime político e não se mantiveram restritos aos que sofreram direta ou indiretamente os desaparecimentos, sendo transmitidos às gerações futuras;

4. Essa experiência tornou obrigatório viver em um conflito permanente entre lembrança e esquecimento;

5. A presença do trauma no presente, bloqueia ou anula possibilidades de ação para o futuro;

6. Os acontecimentos passados são compulsivamente reexperimentados no presente;

7. Não há uma distância temporal, nem de ideias entre o passado e o presente;

8. O trauma atormenta o indivíduo e a comunidade.

Bauer (2012) conclui que o desaparecimento foi a maior forma de implantação do terror e do medo; esta sensação foi a maneira mais eficiente de dominação. Em relação a 
outros países da América Latina que tiveram ditaduras, a Argentina foi o que mais teve desaparecidos. Enquanto no Brasil o número de casos chegam aos 400, no país vizinho há pesquisas que apontam entre 9 e 30 mil casos. Esses dados não podem sustentar a ideia de que a ditadura argentina foi pior do que a ditadura brasileira, caso contrário, estaríamos comparando intensidades de dores.

Em seu livro Brasil e Argentina: ditaduras, desaparecimentos e políticas de memória, Caroline Bauer (2012) se indaga sobre os motivos do alto número de desaparecidos na ditadura argentina. Conforme a autora, a Argentina, por ser o último país do cone sul a entrar em regime ditatorial (1976-1983), o país teria sido local de exilados dos países vizinhos, teria aperfeiçoado os sistemas de repressão através da experiência de outros países e tentaram se distanciar de experiências ditatoriais ineficientes e agressivas no combate à subversão, como é o caso do Chile. A escolha pelo desaparecimento seria mais efetivo, pois evitaria reações externas e internas, imobilizando desta forma os "inimigos".

Os desaparecimentos poderiam ser temporários ou definitivos. O intuito desses atos era a obtenção de informações, através de tortura e interrogatório, que orientassem as ações de captura; a confissões de culpabilidade de atividades subversivas; quebrar e confrontar a resistência da vítima e punir os presos. Conseguindo ou não as informações desejadas, o aparato repressivo matava ou desaparecia com o corpo do interrogado. A falta de informações desestruturava psicologicamente as vítimas e todos que presenciavam os sequestros violentos. Depois do sequestro, a demora para a realização do interrogatório aumentava a tensão dos sequestrados. Toda essa sequência de medidas (sequestro, interrogatório, tortura, desinformação e desaparecimento) produzem uma sociedade traumatizada, emocionalmente fragilizada e impotente perante o governo autoritário. O trauma altera a estrutura interna da vítima, influenciando a maneira de interpretar as situações externas, mas também os eventos internos. Para além disso, segundo Bauer (2012), o trauma pode levar a uma ruptura com a realidade, provocar sentimentos de ansiedade e fomentar o desenvolvimento de fobias.

A cultura do medo que se instalou na Argentina teve como uma de suas gêneses a lógica da suspeição. Qualquer pessoa poderia ser acusada de subversão, o que causa temor de que "a minha vez vai chegar". Cabe salientar, conforme revisão bibliográfica realizada, que o terror foi uma opção articulada e bem desenvolvida dos civis e militares responsáveis pela ditadura argentina, não uma fatalidade. Também é de extrema relevância pontuar que o 
extermínio à dissidência e à oposição política eram feitas através de métodos clandestinos, que tinha como vantagem não deixar vítimas e, por conseguinte, culpados.

\section{Jogos e ensino de história}

Por qual razão utilizar jogos em sala de aula pode ser útil para refletir e debater sobre a Ditadura Civil-Militar Argentina? Acreditando que os alunos podem se envolver mais com os conteúdos, com a própria história e até construir uma consciência histórica através de outros materiais didáticos sem ser o livro, que a proposta de jogo de cartas se justifica. Segundo pesquisa publicada no site O Globo em 2017, o Brasil é o maior consumidor de games, jogos online e de tabuleiro na América Latina. Então, porque não utilizar esse consumo, principalmente dos jovens, em prol do ensino de História e da criação de novas realidades? Conforme Huizinga (2000, p.14), a representação criada pelo jogo é a "realização de uma aparência": imaginação, no sentido original do termo, tendo como função "dois aspectos fundamentais que nele encontramos: uma luta por alguma coisa ou a representação de alguma coisa". Para além disso, o jogo "transcende as necessidades imediatas da vida e confere um sentido à ação" (HUIZINGA, 2017, p.04).

Pereira (2013, p.19) afirma que, no ato de jogar "os estudantes estão na origem dos conceitos, pois que ali, no ato, conceitos históricos se gestam e passam a dar forma à vida, aos modos de vida, aos antigos presentes". No livro Juego, figuración, símbolo: El Tablero de la Oca, Vázquez de Parga estuda a representação dos jogos nas artes plásticas. Segundo a autora, os jogos estão intrinsecamente relacionados à história, pois estes seguem algumas premissas:

1)Produce algún tipo de disfrute a quienes en él participan. 2) Se desarrolla en un espacio y un tiempo ficticios y paralelos a la vida real. 3) Cuenta com unas normas o reglas de actuación delimitadas y aceptadas por convenio. 4) Se establece un orden absoluto en el transcurso de la partida. 5) crea cierta tensión y tiende a una resolución. (VÁZQUEZ DE PARGA, 2008, p. 35).

Para Queiroz (2012), ensinar história requer um diálogo permanente com diferentes saberes. Ainda conforme o autor, a história reconstrói, explica e compreende o seu objeto. Desta forma, propondo este jogo, o professor se distancia daquela ideia tradicional de ensinar como uma reprodução de ideias, saberes e valores; de ver o aluno como um repositório de informações, causando-lhe a falta de criatividade, de construção e transformação dos saberes. Acredito também nas ideias de Seffner (2010), qual diz que a aula de história tem como objetivo produzir saberes de natureza histórica relevante ao aluno, que sirva como impulsionadora de questionamentos da realidade e de sua vida. Sendo assim, a aula serve para o desenvolvimento da consciência histórica. 
O conceito de consciência histórica que me refiro é o apresentado por Cerri (2011), qual diz: "no agir sobre o mundo e ser sujeito da história, o passado e suas projeções de futuro são tudo o que está à disposição do homem, como matéria-prima para a sua criação". Ou seja, o agir sobre o mundo é uma atribuição de consciência histórica, pois o deixar de agir revela igualmente uma interpretação da realidade. Esse agir sobre a realidade significa interpretar o passado à luz do presente e na expectativa do futuro.

Cabe ressaltar que, seguindo a perspectiva de Circe Bittencourt, considero os materiais didáticos como suporte na mediação entre o ensino e aprendizagem. No caso em questão, o jogo teria o papel de facilitar a apreensão de conceitos, o domínio de informações, favorecer possíveis sistematizações de dados e, consequentemente, a construção do conhecimento. Ainda nessa linha, o jogo seria uma ilustração, como Bittencourt (2009) define: instrumento de reforço do que já foi trabalhado.

Aprofundando nas ideias de Bittencourt, trago outras reflexões sobre os jogos como material didático. Segundo o dicionário Escolar de Língua Portuguesa Aurélio, jogo significa:

\begin{abstract}
Atividade física ou mental fundada em sistema de regras que definem a perda ou ganho. Passatempo. Jogo de azar. O vício de jogar. Série de coisas que forma um todo, ou coleção. Conjugação harmoniosa de peças mecânicas com o fim de movimentar um maquinismo. Balanço, oscilação. Manha, astúcia (FERREIRA, 2011, p. 534).
\end{abstract}

Como podemos perceber, há uma miríade de significados, todavia utilizaremos o conceito de jogo trabalhado por Grando (1995). Para a autora, existem seis classificações para os jogos: os de azar, quebra-cabeça, estratégia, computacionais, jogos de fixação de conceitos e pedagógicos. Neste trabalho, utilizaremos as duas últimas classificações. Os jogos de fixação de conceitos são aqueles cujo objetivo é fixar um determinado conceito/conteúdo já aprendido em outras aulas. Este tipo de jogo substitui, muitas vezes, as avaliações tradicionais, como a prova escrita. Os jogos pedagógicos são aqueles que podem ser utilizados durante o processo de ensino-aprendizagem.

Pensando na utilização dos jogos na aula de matemática, Grando (2000, p.43-45) propõe sete etapas para a utilização de jogos em sala de aula: a familiarização com o material do jogo (no sentido físico do material didático), o reconhecimento das regras (aquelas determinadas pelo produtor do jogo), o "jogo pelo jogo", a intervenção pedagógica verbal (momento de levantamento de questões referentes à temática e observação), registro do jogo, intervenção escrita e jogar com competência. Estas etapas também serão aplicadas ao jogo proposto. 
Como a própria Bittecourt (2009) pontua, escolher um material didático requer sensibilidade do docente para com a adequação idade/série dos alunos. Pensando nisso, o jogo proposto tem como público alvo os alunos do ensino médio e dos anos finais do ensino fundamental, devido a temática problemática, delicada e embaraçosa que o mesmo aborda; tendo em vista também os dias atuais, nos quais a própria ditadura brasileira de 1964 não tem recebido as devidas reflexões pela massa popular. A ditadura civil-militar que a Argentina vivenciou durante os anos de 1976 e 1983, gerou traumas na sociedade que ainda são visíveis, seus desdobramentos são constantemente revisitados e, numa perspectiva gumbrechtiana, ainda se encontram em estado de latência. As mortes, os desaparecimentos, sequestros, as adoções ilegais são algumas das heranças deixadas por aquele período. É nesse aspecto (da latência da ditadura e do Terror de Estado) que o jogo de cartas produzido trabalha.

\section{O jogo}

Considerando a importância da empatia para a prevenção e reparação de eventos traumáticos, o grande objetivo desse jogo é construir uma ideia da ditadura argentina como um evento potencialmente traumático, com foco nas políticas de segurança nacional e Terror de Estado, situando os jogadores na sensação de vulnerabilidade, na qual os viventes daquele período experienciaram. Cabe reforçar que o jogo não se expressa por si só, ou seja, ele é um suporte para o professor utilizá-lo após outras aulas sobre as ditaduras na América Latina, ou seja, o material didático aqui relatado é um objeto de fixação de conteúdos, como Grando propõe. Destarte, seguindo a concepção de Bittecourt, a atividade se expressa como uma espécie de ilustração, pois reforça o que já foi trabalhado em outras aulas.

Elaborado no intuito de ser aplicado conforme as sete etapas de utilização do jogo em sala de aula, proposto por Grando, tal material didático contém 85 cartas: desaparecido, sequestrado, torturado, estou com medo, suspeito de subversão/desordem, censurado, detido, desinformado, interrogado, vizinho sumiu, familiar sumiu, entrei em esquecimento, desaparecimento definitivo, desaparecimento temporário, oposição política, direitos humanos e a abominável e temida carta Terror de Estado e Segurança Nacional. Cada grupo de cartas tem uma cor: as verdes significam que o jogador, mesmo consciente da sua vulnerabilidade perante o Estado, continua vivendo sua vida, ou seja, continua no jogo. Algumas delas podem até unir forças com outro cidadão, outro jogador, para derrotar o regime militar e o Terror de Estado. As laranjas significam um estado de alerta e apreensão dos cidadãos/jogadores. $\mathrm{O}$ conjunto de 3 ou 4 cartas dessa cor, elimina imeditamente o jogador. As cartas vermelhas 
expressam a detenção de poder ou a sua falta; podem eliminar qualquer pessoa/jogador e se defender de possíveis uniões subversivas, ou ainda, apenas sair do jogo. Existe também uma carta à parte que explícita as regras do jogo. Vence aquele jogador (ou grupo de jogadores) que ficar por último.

Para aventurar-se nesse material didático é necessário ter no mínimo 8 jogadores. As chances do terror de Estado ganhar são maiores. Isso se deve, em certa medida, ao maior número de cartas laranjas, pois estas dão o tom para a proposta do jogo. As cartas laranjas apontam para a "lógica da suspeição" (BAUER, 2012), qual foi implantada na ditadura argentina. A sociedade como um todo era vista como possíveis inimigos, o que garantiu o sucesso da ditadura no país em questão, corroborando para a efetivação do terror físico, ideológico e psicológico.

\section{Conclusões}

Se a História é exemplar, nos ajudando a não cometer os mesmos erros do passado no presente, devemos então nos aproximarmos dela. Ao estabelecer esta relação com a história, precisamos dar ouvidos e ampliar as vozes que gritam e lutam por reparações sociais que o Estado tende a silenciar. Ao sermos silenciados, nossa ação é limitada, sendo muitas vezes esse silêncio, uma dificuldade de interpretar e representar eventos que foram traumáticos. Neste sentido, o jogo de cartas proposto, como defendido teoricamente, se torna um instrumento didático riquíssimo de representação da realidade, corroborando para o processo de sistematização dos conteúdos entre os discentes/seus jogadores, principalmente pelo fato das informações não estarem completas nas cartas, necessitando de atividades cognitivas de significação por parte dos alunos. Ao significar conteúdos que não estão dados, nem prontos, tornamos o passado em presente e agimos sobre ele.

\section{Referências}

ALVES, Maria Helena Moreira. “A doutrina de Segurança Nacional e Desenvolvimento”. In: . Estado e Oposição no Brasil. Petrópolis; Ed. Vozes, 1989.

BARROS, José D’Assunção. História, região e espacialidade. Revista de História Regional 10(1): 95-129, Verão, 2005, pp. 95-129. 
BAUER, Caroline Silveira. Brasil e Argentina: ditaduras, desaparecimentos e políticas de memória. Porto Alegre: Medianiz, 2012.

BITTECOURT, Circe. Livro didático / Usos didáticos de documentos. In: BITTENCOURT, Circe. Ensino de História - fundamentos e métodos. São Paulo: Cortez, 2009.

BORDA BOHIGAS, Juan Pablo; CARRILLO, Juan O.; GARZÓN, Daniel F.; RAMÍREZ, María P.; RODRÍGUEZ, Nicolás. Trauma histórico. Revisión sistemática de un abordaje diferente alconflicto armado Revista Colombiana de Psiquiatría, vol. 44, núm. 1, 2015, pp. 41-49.

CERRI, Luis Fernando. O que é consciência histórica? In: CERRI, Luis Fernando. Ensino de História e consciência histórica: implicações didáticas de uma discussão contemporânea. Rio de Janeiro: Editora da FGV, 2011.

FERREIRA, A. B. H. Aurélio Júnior: dicionário escolar de língua portuguesa. Curitiba: Positivo, 2011.

FREIRE, Paulo. A concepção "bancária" da educação como instrumento de opressão / Seus pressupostos, sua crítica. In: FREIRE, Paulo. Pedagogia do oprimido. Rio de Janeiro: Editora Paz e Terra, 2005.

GRANDO, R. C. O conhecimento matemático e o uso de jogos na sala de aula. Tese de Doutoramento em Educação - Faculdade de Educação, Universidade Estadual de Campinas, Campinas, 2000. Disponível em: < https://pedagogiaaopedaletra.com/wp-content/uploads/2012/10/O-CONHECIMENTOMATE M\%C3\%81TICO-E-O-USO-DE.pdf >. Acesso em: 10 de Novembro de 2018.

GRANDO, R. C. O jogo e suas possibilidades metodológicas no processo ensino-aprendizagem da matemática. Campinas, SP, 1995. 175p. Dissertação de Mestrado Faculdade de Educação, UNICAMP. Disponível em: < http://repositorio.unicamp.br/jspui/handle/REPOSIP/253786/ >. Acesso em: 10 de Novembro de 2018.

GUMBRECHT, Hans Ulrich. Depois de 1945: latência como origem do presente. Ed. Unesp; Edição 1, 2014.

HUIZINGA, Johan. Homo Ludens: o jogo como elemento da cultura. São Paulo: Perspectiva, 2017. 
O GLOBO. Jogos online movimentam 49 bilhões e Brasil lidera o setor na América Latina. Disponível em < https://oglobo.globo.com/economia/jogos-on-line-movimentam-49-bilhoesbrasil-lidera-setor-na-america-latina-21014736 >. Acesso: 01 de Julho de 2018.

PADRÓS, Enrique Serra. Introdução. In: Como el Uruguay no hay... Terror de Estado e Segurança Nacional. Uruguai (1968-1985): do Pachecato à Ditadura civilmilitar. Tomo I. Porto Alegre. Tese de Doutoramento apresentada ao Programa de Pós-graduação em História da UFRGS, 2005.

PEREIRA, Nilton Mullet. GIACOMONI, Marcelo. Flertando com o Caos: os jogos no Ensino de História. In: PEREIRA, Nilton Mullet. GIACOMONI, Marcelo. Jogos e Ensino de História. Porto Alegre: Evangraf, 2013.

QUEIROZ, Paulo Pires. A pesquisa e ensino de História: espaços/processos de construção de identidade profissional. In: NIKITUK, Sônia. Repensando o Ensino de História. São Paulo: Cortez Editora, 2012.

SEFFNER, Fernando. Saberes da docência, saberes da disciplina e muitos imprevistos: atravessamentos no território do ensino de História. In: BARROSO, Vera Lucia Maciel (org.). Ensino de História: desafios contemporâneos. Porto Alegre: EST, Exclamação, ANPUH-RS, 2010.

TODOROV, Tzvetan. "Narrar, julgar, compreender”. In: . Em face do extremo . Campinas: Papirus, 1995.

VÁZQUÉZ DE PARGA, María José Martínez. Juego, figuración, símbolo: El Tablero de la Oca. Madri: 451 editores, 2008. 